\title{
Universidade Católica hoje
}

\author{
The Catholic university today
}

Mario de França Miranda

\section{Resumo}

O texto aborda o desafio atual posto pela sociedade pluralista à Universidade Católica, já que este pluralismo, cultural e religioso, se encontra hoje também dentro da própria instituição. Daí a dificuldade para esta última de realizar sua missão de evangelizar. Depois de sintetizar a identidade da Universidade Católica, expressa na Constituição Ex Corde Ecclesiae, o autor propõe um ponto de partida mais amplo para o anuncio da fé cristã, a saber, o cuidado com o ser humano, à luz da mensagem do Reino de Deus, que necessariamente carrega consigo os valores cristãos, embora ainda não nomeados como tais. Deste modo reflete sobre o humanismo cristão, seus valores e suas expressões, que podem mesmo não ser religiosas.

Palavras-chave: Universidade Católica; Evangelização; sociedade pluralista.

\begin{abstract}
The text presents the current challenge posed by pluralistic society to the Catholic university. This cultural and religious pluralism is already encountered today also within the selfsame institution, which creates difficulty for the Catholic university to fulfill its mission to evangelize. After synthesizing the identity of the Catholic university expressed in the Constitution, Ex Corde Ecclesiae, the author proposes a broader starting point for announcing the Christian faith: that is to say, care with the human being in light of the message
\end{abstract}


of the Reign of God, which necessarily carries with it the Christian values, even though not yet named as such. In this way, the text reflects on Christian humanism, its values and its expressions, which might not even be religious.

Keywords: Catholic university; Evangelization; pluralistic society.

\section{Introdução}

O objetivo desta reflexão não consiste propriamente em caracterizar ou mesmo definir o que seja uma Universidade Católica. Sobre esta instituição eclesial dispomos já de ricas contribuições por parte de historiadores, do magistério eclesiástico, de sociólogos e de teólogos. Por isso mesmo vamos assumir como fundamento deste estudo a importante Constituição Apostólica do papa João Paulo II sobre as Universidades Católicas, mais conhecida como Ex Corde Ecclesiae. Ela nos fornecerá as características essenciais que garantem a identidade de uma Universidade Católica e nos indicará sua missão específica diante da Igreja e da sociedade. Entretanto esta instituição como realidade histórica existe somente inserida numa determinada época e num contexto sociocultural concreto. Sabemos, por outro lado, que as épocas se sucedem e que os contextos socioculturais se transformam. Sabemos também que a Universidade Católica não consegue deixar de ser atingida por tais mudanças da sociedade e da cultura. E que estas mudanças podem dificultar sobremaneira sua inserção no meio acadêmico e sua missão evangelizadora. Vivemos num tempo de crise geral das instituições tradicionais, família, escola, organização política, para citar algumas, e a Universidade Católica também se vê questionada em seus objetivos. Daí o advérbio "hoje" do nosso título, que constituirá também o fio condutor desta reflexão, já que todo o nosso intento é oferecer uma proposta que facilite à Universidade Católica manter sua identidade e realizar sua missão em nossos conturbados dias.

Naturalmente o tema é bastante complexo. Portanto, já de início, que fique bem claro que não o abordaremos em toda sua amplitude. Questões como a liberdade de pensamento e de pesquisa, de um lado, e fidelidade à fé cristã e à Igreja, de outro, embora cruciais, não serão objeto de nossa reflexão. Interessa-nos sobretudo a atual situação da Universidade Católica numa sociedade pluralista que dela exige inovações, desde que pretenda realizar seriamente sua missão. Pois sua primeira reação à cultura moderna foi, como as demais instituições católicas do passado, considerá-las como "redutos de 
cristandade" que garantissem a vida cristã dos católicos numa sociedade vista como hostil e maléfica ${ }^{1}$. Consequentemente havia um controle sobre os temas de ensino e pesquisa, sobre a lealdade dos docentes, sobre a transmissão fiel dos valores cristãos aos estudantes. Michael J. Buckley as caracteriza como "custodial institutions", indicando a problemática continuidade deste modelo de universidade em nossos dias ${ }^{2}$. Este será o nosso ponto de partida em direção não a uma solução pronta e acabada, mas como uma nova perspectiva que permita o diálogo aberto e a colaboração de todos numa instituição que não se situa somente diante de uma sociedade pluralista, mas que, queira ou não, abriga em seu seio o pluralismo. Trata-se portanto de mostrar a necessidade desta nova perspectiva, de fundamentá-la e de apresentar suas consequências para a missão da Universidade Católica.

Veremos brevemente numa primeira parte as características essenciais da Universidade Católica segundo o texto da Ex Corde Ecclesiae. Em seguida examinaremos as dificuldades postas pela atual sociedade à existência e à missão desta instituição eclesial. Numa terceira parte tentaremos desfazer representações e mentalidades encontradas no imaginário católico que não mais se justificam e só agravam ainda mais o problema. Numa quarta parte exporemos então como a preocupação com o ser humano pode ser o ponto de partida para que a Universidade Católica possa melhor desempenhar sua missão em nossos dias. E, finalmente, concluiremos apresentando as vantagens desta proposta.

\section{Identidade e Missão da Universidade Católica}

Não podemos separar identidade e missão, pois a Universidade Católica é uma instituição a serviço da Igreja, a qual, por sua vez, recebe todo o seu sentido (identidade) ao proclamar e realizar na história o Reino de Deus, inaugurado em Jesus Cristo (missão). Portanto é a missão que qualifica esta instituição universitária, a qual deve contribuir para o progresso do conhecimento humano, no serviço ao Povo de Deus e à sociedade, mantendo fidelidade à mensagem cristã, e inspirando assim a comunidade universitária (Ex Corde Ecclesiae n. 13). Com outras palavras, dirigir o estudo e a pesquisa para

\footnotetext{
${ }^{1}$ KOMONCHAK, J. A. Modernity and the Construction of Roman Catholicism. Cristianesimo nella Storia 18 (1997), p. 353-385.

${ }^{2}$ BUCKLEY, M. J. The Catholic University as Promise and Project. Washington: Georgetown University Press, 2007, p. 133-135.
} 
uma maior integração do conhecimento, hoje tão difícil pela pluralidade das disciplinas e de suas respectivas hermenêuticas; estabelecer um diálogo sério entre razão e fé, esta última continuamente desafiada pelas novas conquistas científicas; enfatizar a dimensão ética no emprego de métodos de pesquisa e em suas descobertas, já que estão a serviço do ser humano; oferecer às demais disciplinas um horizonte teológico que ultrapasse suas respectivas fronteiras e que facilite sua interação (n. 14-19). Como qualquer instituição deste nível a Universidade Católica deve estar a serviço da sociedade estudando os graves problemas contemporâneos (n. 32), enfatizando a importância da justiça social (n. 34), criticando as contradições da cultura atual (n. 45).

Examinando mais de perto as orientações desta Constituição Apostólica constatamos presente e recorrente ao longo de seus capítulos a preocupação com o ser humano em toda sua plenitude. Seja a busca sincera da verdade, pressuposto para um "humanismo universal" (n. 4), seja a mútua colaboração em cada pessoa da razão e da fé em vista da "medida plena de sua humanidade" (n. 5), seja a consideração das diversas disciplinas "no quadro de uma visão da pessoa humana e do mundo iluminada pelo Evangelho" (n. 16), seja a importância "da autêntica antropologia cristã" (n. 33), volta sempre o critério fundamental, a saber, "o sentido da pessoa humana, a sua liberdade, a sua dignidade, o seu sentido de responsabilidade e a sua abertura ao transcendente" (n. 45), como acentua mais recentemente o papa Francisco: "sempre respeitem a centralidade e o valor supremo da pessoa humana em todas as fases de sua existência" (EG 242).

\section{O desafio da atual sociedade pluralista}

A cosmovisão cristã que fornecia no passado sentidos e valores à vida social, viu se emanciparem sucessivamente vários setores da sociedade, como o político, o científico, o econômico, o antropológico, gerando um pluralismo de âmbitos do saber dotados de racionalidades e de normatividades próprias. Foi uma emancipação tensa, conflitiva e difícil que terminou com uma delimitação mais clara do que compete à razão e à fé. Entretanto experimentamos em nossos dias o controle hegemônico da sociedade por parte da economia, que tudo submete ao imperativo da produtividade e do lucro. As demais realidades sociais são assim instrumentalizadas e avaliadas apenas como mercadorias pelo seu valor de troca. Por outro lado o progresso científico e tecnológico provoca transformações sucessivas e rápidas na sociedade, questionando 
instituições tradicionais e referências substantivas vigentes no passado, sem oferecer alternativas consistentes à pessoa humana que acaba cedendo ao individualismo de cunho hedonista e materialista e à ânsia do consumismo. A preocupação pelo bem comum, a consciência ética, sonhos e anseios que ultrapassem os interesses pessoais se tornam fora de moda.

As consequências funestas desta realidade são bem conhecidas: crescem as desigualdades sociais, aumentam os sofrimentos humanos, explodem situações de violência, exclui-se grande parte da população mundial dos benefícios do progresso, destrói-se cinicamente com a exploração desenfreada o próprio habitat humano ameaçando a sustentabilidade de vida no planeta. Naturalmente esta hegemonia do fator econômico não se detém às portas da universidade ${ }^{3}$. Esta que nasceu na Idade Média separada do poder, viu-se a partir do século XVI posta a serviço do poder político e militar, e encontra-se em nossos dias fortemente dependente do poder econômico ${ }^{4}$.

Observemos ainda que o pluralismo já é uma realidade no interior das Universidades Católicas, que apresentam em seu corpo docente e entre seus estudantes uma grande diversidade de mentalidades, crenças religiosas, tradições culturais, classes sociais. Daí a grande dificuldade de uma linguagem comum, acessível a todos os grupos, que sirva de mediação para a presença e a atuação dos valores cristãos como deseja nossa Constituição Apostólica. Acrescentemos a esta constatação que a diversidade das disciplinas, dotadas todas elas de racionalidade e normatividade próprias, acaba por moldar mentalidades diversas, para não dizer mundos fechados, que resistem às indagações que ultrapassem suas fronteiras ${ }^{5}$. Deste modo resulta extremamente problemático o discurso da fé cristã que aborda as questões últimas como o sentido da vida, o enigma do mal, o desafio do sofrimento e da morte. Pode também acontecer que tais racionalidades parciais falham ao ignorar seus limites epistemológicos e ao querer dar respostas falsas a problemas de outra ordem $^{6}$, como podemos verificar entre alguns cientistas em nossos dias que ajudados pela publicidade conseguem sucesso de vendas.

\footnotetext{
${ }^{3}$ Ver o excelente estudo de AGUIAR PEREIRA, E. M. A Universidade da modernidade nos tempos atuais. Avaliação 1 (2009), p. 29-52.

${ }^{4}$ ZAMAGNI, S. A identidade e a missão de uma universidade católica na atualidade. Cadernos IHU Ideias 11 (2013), p. 5s. Como confirmação este autor cita a Declaração de Lisboa (2007) e a resume deste modo: a universidade deve se estruturar em função do emprego futuro dos estudantes, enfatizando a instrução e não a formação; a pesquisa se transformou numa competição e vale pela sua rentabilidade (Ibid. p.6-8).

${ }^{5}$ Ver FRANÇA MIRANDA, M. Igreja e sociedade. São Paulo: Paulinas, 2009, p. 44-52.

${ }^{6}$ MARION, J.-L. "Le service de la rationalité dans l'Église". In: J.-L. MARION, Le croire pour le voir. Paris: Parole et Silence, 2010, p. 101s.
} 
Temos que reconhecer entretanto que o desafio maior provém da própria Igreja que carece de quadros católicos competentes, imprescindíveis para um diálogo com esta diversidade dentro da Universidade. Com raríssimas exceções o episcopado não investe em vocações intelectuais no clero e no laicato. A presença e a atuação da fé se limita a doutrinamentos e celebrações religiosas que pouco dizem para a maioria, ainda refém de representações infantis da fé cristã, não mais compatíveis com a consciência crítica a que chegaram, tornando assim o investimento evangelizador inócuo e estéril. Nota-se também da parte de alguns mais preocupados e comprometidos com os mais desfavorecidos um certo distanciamento das celebrações e das práticas religiosas. Também faltam espaços de escuta e de diálogo no interior da Universidade para conhecermos melhor o nosso público, suas indagações, seus preconceitos, seus anseios, suas representações e seus questionamentos. Naturalmente ouviremos o que não nos agrada, o que nos choca, o que talvez nos obrigue a pensar, o que nos force estudar. Urge uma mudança de mentalidade por parte dos responsáveis que mais fomentasse a liberdade de expressão e a cultura do diálogo no interior do campus universitário.

\section{Um novo ponto de partida}

A preocupação com o ser humano, cuja identidade integral deve ser respeitada e cuja vocação cristã deve ser anunciada e vivida, ficou clara na Constituição Ex Corde Ecclesiae como pudemos constatar. Esta preocupação entretanto não é apenas encontrada na Igreja, já que presente em todos aqueles que lutam pela verdade nas relações humanas, pela justiça social na sociedade, pela paz no mundo, pela diminuição dos sofrimentos provindos da violência, pelo fim das discriminações e dos preconceitos. Certa sensibilidade humana pelo outro, embora sempre possamos apresentar pessoas e fatos que a enfraquecem, embora também em muitos permaneça sem concretizações visíveis, aparece hoje como um anseio comum em muitos de nossos contemporâneos.

Daí nasce a pergunta: se este anelo humanista está presente não só nos pronunciamentos da Igreja, mas também nos corações das pessoas de boa vontade, não constituiria ele uma base comum a partir da qual poderia ser anunciada a mensagem cristã e, mais concretamente, a missão evangelizadora da Igreja na Universidade Católica? Estaríamos aqui optando por iniciar não com enunciados doutrinais ou celebrações sacramentais, que marcaram muito a pastoral de manutenção do passado, sem negar, de modo algum, sua neces- 
sidade permanente para a identidade da Igreja, mas estaríamos assumindo uma motivação existencial, presente e atuante na vida daqueles que não se conformam com o atual cenário do planeta.

À primeira vista pode parecer que renunciamos a uma proclamação explícita da mensagem cristã no âmbito da Universidade Católica. Conseguimos uma base comum, mas de tal modo ampla e indiferenciada que não mais poderia ser caracterizada como cristã. Podemos aceitar esta afirmação? Ou baseia-se ela em representações da fé que, de fato, não são corretas? Neste caso teríamos que demonstrar serem tais concepções falsas e infundadas. É o que faremos a seguir.

A preocupação com o ser humano atravessa a Bíblia de ponta a ponta. Ela expõe o projeto de Deus de fazer a humanidade participar de sua felicidade. Contudo o pecado constituiu um obstáculo à sua realização. Daí a necessidade de educar um povo, de constitui-lo como seu povo através da Torá e de líderes como Abrão, Moisés e os profetas. Sendo o ser humano essencialmente social este projeto de Deus visava à constituição de uma sociedade sob a soberania de Deus, à realização do Reino de Deus que, por não conseguir se tornar realidade perfeitamente, é então projetada para o futuro. Este é o quadro de fundo que dá sentido às palavras e às ações de Jesus Cristo. Ao iniciar sua vida pública proclama claramente que este Reino irrompe definitivamente em sua pessoa (Mc 1,15s; Lc 4, 21). Daí que toda a sua vida consistirá em promover este Reino. Assim suas ações buscam socorrer os que sofrem, os marginalizados, os desesperançados, os pecadores, os pobres (Mt 11,5). Suas palavras visam à implantação de uma sociedade fraterna e justa na obediência à vontade de Deus. O Povo de Deus é a família de Deus (Mc 12, 48-50), mas também pode ser considerado uma sociedade alternativa à sociedade marcada pelo egoísmo humano, pela injustiça e pelo sofrimento dos mais fracos, antecipação da comunidade celeste?

Portanto a fé cristã não se dirige a um Deus qualquer, mas ao Deus de Jesus Cristo, ao Deus do Reino, ao Deus cuja ação salvífica na história humana se realiza através de homens e mulheres que, vencendo suas tendências egocêntricas, se dedicam a ajudar os mais necessitados e a viver a aventura do amor cristão. Portanto, crer no Deus do Reino implica ser um fator de humanização da sociedade. Esta é a verdadeira fé que atua pelo amor (Gl 5,6).

\footnotetext{
${ }^{7}$ LOHFINK, G. Deus precisa da Igreja? Teologia do povo de Deus. São Paulo: Loyola, 2008; LOHFINK, G. Jesus von Nazareth. Was er wollte, wer er war. Freiburg: Herder, 2011 (LOHFINK, G. Jesus of Nazareth. What He Wanted, Who He Was. Collegeville: Liturgical Press, 2012).
} 
Por conseguinte, nas palavras do papa Francisco: "Evangelizar é tornar o Reino de Deus presente no mundo" (EG 176).

Estamos às voltas com o núcleo da fé cristã. Na vivência da caridade fraterna obedecemos ao Pai, nos conformamos a Cristo e seguimos os impulsos do Espírito (G1 5,25). Este núcleo é bem mais importante do que suas expressões e suas práticas, por mais necessárias que sejam. Já foi observado que Jesus teve uma postura crítica com relação à religião de seu tempo, relativizando seus preceitos em favor do ser humano em necessidade, como nos atestam os vários episódios narrados pelos evangelistas, especialmente a parábola do bom samaritano (Lc 10, 25-37) e o solene discurso sobre o juízo final (Mt 25, 31-46). Assim o sagrado para Jesus era o próprio ser humano. Ele não quis acabar com a religião, mas levá-la a sua plena realização (Mt 5,17), que unia o culto ao Pai com o cuidado com o irmão, que assumia a vida humana em toda a sua complexidade, que não separava sagrado de profano, que determinava se dar o encontro com Deus nas próprias ações cotidianas em favor do projeto de Deus ${ }^{8}$.

Por outro lado, este núcleo da fé cristã não exclui que seja expresso em doutrina, ganhe corpo no culto, se submeta a normas morais e se institua como comunidade de fiéis. Mas já Santo Tomás de Aquino observava: a religião não é a fé, apenas os sinais exteriores que a manifestam (S. Th. II-II, 94, 1 ad $1)^{9}$. Naturalmente a vida da fé necessita de tais sinais exteriores que a tornam mais consciente, mais lúcida, mais forte. Entretanto nos perguntamos se o cristianismo não se prendeu demasiado à dimensão religiosa da fé, deixando em segundo plano sua dimensão mais propriamente evangélica. Esta constatação histórica era alicerçada numa funesta separação entre natureza e graça, entre o cotidiano e o salvífico, que marcou fortemente o inconsciente católico no passado, afastando a fé cristã da vida concreta. Embora esta concepção se encontre hoje superada, ainda não deixa de ter consequências sérias para a presença e atuação da fé cristã na Universidade Católica, como veremos.

Entretanto ao afirmar a centralidade do amor fraterno no cristianismo, ao considerar o ser humano como o local de encontro com Deus, ao investir nossa liberdade, nossa vida, na luta para salvar a dignidade do ser humano, não poderia o cristianismo perder assim sua identidade, já que tal sensibilidade, tal motivação, tal empenho, pode ser encontrado também em muitos que não

${ }^{8}$ CASTILlO, J. M. La humanización de Dios. Ensayo de Cristologia. Madri: Trotta, 2009, p. 93-117.

${ }^{9}$ ROLLET, J. "Religion et foi. L'actualité d'une différence". In: J. DORÉ, Ch. THEOBALD (dir.), Penser la Foi. Mélanges offerts à Joseph Moingt. Paris: Cerf, 1993, p. 301-313. 
professam a fé cristã? Não seria reduzir o cristianismo a um simples humanismo? Onde estaria sua referência a Deus, ao Transcendente? Tais questões pedem uma reflexão ulterior sobre a natureza simbólica do próprio cristianismo.

Pois Deus, enquanto realidade transcendente, só pode se fazer presente e atuante em nosso mundo, só pode se manifestar nas realidades a nós acessíveis. Deste modo tais realidades ganham a qualificação de remeterem a pessoa a outra realidade, deixam transparecer em si o que não são de fato. Podemos caracterizar tais realidades como símbolos em sentido denso. Pois não são meros sinais convencionais, como os semáforos do tráfego, já que participam e compartilham de algum modo a realidade nelas simbolizada ${ }^{10}$. Esta afirmação vale tanto para uma celebração sacramental quanto para a vida de um santo. De fato, no cristianismo tudo pode ser visto em sua característica simbólica: a Bíblia, a comunidade eclesial, os sacramentos, os dogmas, pois aí estão não como meta final, mas para nos remeterem para Deus. Já observava Santo Tomás que o ato de fé não se detém no enunciado, mas se dirige para a realidade nele expressa. E como Deus se revela ao vir nos salvar, tais realidades simbólicas são sinais salvíficos, que devem ser captados e acolhidos pelo ser humano para que neles se faça presente e atuante a realidade que significam.

Este ponto é importante. O símbolo salvífico deve ser entendido ou interpretado em sua verdade simbólica. Eles requerem portanto um olhar, um envolvimento pessoal, uma intencionalidade explícita e consciente para que possam se manifestar em toda a sua verdade ${ }^{11}$. O que significa a Bíblia ou uma celebração eucarística para quem não tem fé? Chegados a este ponto vislumbramos duas causas para certa indiferença religiosa em nossos dias e que atingem também nossas Universidades Católicas. A primeira provém dos próprios símbolos cristãos que, por se apresentarem numa linguagem arcaica, não são mais devidamente entendidos. Como afirma o papa Francisco: "somos fiéis a uma formulação, mas não transmitimos a substância" (EG 41). A segunda causa é mais desafiante, provem da própria sociedade pluralista e secularizada onde muitos carecem do horizonte interpretativo próprio da fé cristã. Falta-lhes o olhar adequado para serem tocados, sensibilizados, atraídos, movidos pela iniciativa salvífica de Deus expressa nestes sinais.

Duplo desafio que atinge em cheio a própria missão da Universidade Católica. O primeiro deles exige uma renovação da linguagem no cristianismo que constitui o que hoje denominamos a inculturação da fé cristã. Mais problemático é o segundo, pois não mais podemos fazer retroceder a história

\footnotetext{
${ }^{10}$ Ver HAIGHT, R. Dinâmica da Teologia. São Paulo: Paulinas, 2004, p. 149-187.

${ }^{11}$ DUPRÉ, L. L'autre dimension. Essai de philosophie de la religion. Paris: Paris, 1977, p. 126.
} 
para a época da cristandade. Haveria uma linguagem que gozasse de tal universalidade que pudesse atingir a todos em suas diversidades, tal como nos apresenta a atual sociedade pluralista? Poderíamos indicar o testemunho de vida, que manifesta com veracidade o coração, os valores, as convicções de uma pessoa, tornando visível uma realidade invisível. Neste sentido o testemunho do cristão aponta para Jesus Cristo vivo e atuante em sua vida, dando sentido e força à sua existência. Sobretudo porque este testemunho vivo contraria a tendência egocêntrica, individualista, hedonista, predominante na sociedade. Aí se manifestará mais claramente o que este testemunho de amor fraterno implica de renúncia, de sacrifício, de saída de si, que não conseguem ser explicados pela atual cultura. Já Paulo VI afirmava que nossos contemporâneos escutam mais as testemunhas do que os mestres, e se escutam estes últimos é porque eles são testemunhas (Evangelii Nuntiandi 41). Bem conhecemos o impacto que teve em seu tempo o testemunho de vida de Teresa de Calcutá. Mas esta constatação implica imediatamente outras perguntas: por que este testemunho de vida toca tanto as pessoas em nossos dias? Poderia ela ser considerada a linguagem universal que buscamos? É o que veremos a seguir.

\section{O humano cristão: metodologia e significado}

Partir de um anseio comum presente nas pessoas mais conscientes e responsáveis em nossos dias para a missão da Igreja e da Universidade Católica representa uma nova modalidade de proclamar a fé cristã. Não mais partimos das verdades reveladas, já formuladas em doutrinas e normas, buscando numa segunda etapa considerar o que delas se deduz para a realidade humana e social em termos de compreensão e de comportamento. Pois nosso enfoque parte da própria realidade histórica, tal como a experimentamos hoje, para indutivamente chegar à mensagem cristã. Neste ponto adotamos o método utilizado na Constituição Apostólica do Vaticano II Gaudium et Spes, que, sem dúvida, representou uma novidade na história dos Concílios ${ }^{12}$. Este documento reconhece a importância das diversas culturas para a missão evangelizadora, a ajuda que prestam aqueles que "conhecem bem os vários sistemas e disciplinas e entendem a sua mentalidade profunda" e a tarefa

${ }^{12}$ Ver SCHICKENDANTZ, C. Una elipse con dos focos: hacia un nuevo método teológico a partir de Gaudium et Spes. Revista Teología 50 (2013), p. 89-109, aqui p. 96. Ver também SANDER, H.-J. "Theologischer Kommentar zur Pastoralkonstitution über die Kirche in der Welt von heute Gaudium et Spes”. In: P. HÜNERMANN, B.-J. HILBERATH (Hrsg.), Herders Theologischer Kommentar zum Zweiten Vatikanischen Konzil 4. Freiburg: Herder, 2005, p. 581-886, aqui 700-703. 
da Igreja de "auscultar, discernir e interpretar as várias linguagens do nosso tempo e julgá-las à luz da Palavra Divina”. E ainda taxativamente afirma: “A Igreja pode enriquecer-se e de fato se enriquece também com a evolução da vida humana social, não porque the falte alguma coisa em sua constituição que lhe foi dada por Cristo, mas para conhece-la mais profundamente, melhor exprimi-la e adaptá-la de modo mais feliz aos nossos tempos". Pois "todos aqueles que promovem a comunidade humana ... prestam um auxílio não pequeno também à comunidade eclesial" (GS 44).

Nosso método segue na mesma linha deste documento conciliar, mas almeja um objetivo mais modesto. Não pretendemos realizar uma reflexão teológica a partir da história, considerando esta última como um autêntico "locus theologicus", mas simplesmente oferecer uma base comum, gozando assim de certa universalidade, que possa mediar a proclamação da mensagem cristã. Os anseios por um ser humano respeitado em sua dignidade, não reduzido a uma peça da grande engrenagem da economia de mercado, não esvaziado de valores substantivos que não sejam meramente funcionais, se encontram em muitos de nossos contemporâneos, cristãos ou não ${ }^{13}$. Assim como a preocupação com o bem comum, a sensibilidade para com o sofrimento humano, o desconforto com a destruição da natureza, a aflição pela qualidade de vida dos nossos pósteros, estão presentes em muita gente mais lúcida e crítica. Não negamos que muitos destes valores tenham raízes cristãs, embora sejam hoje apresentados em versões secularizadas. Mais adiante examinaremos este ponto.

Resta-nos caracterizar melhor o que entendemos por humano cristão. Naturalmente devemos partir da revelação, ou mais concretamente, da pessoa de Jesus Cristo. A partir do cristocentrismo da criação devemos afirmar que toda a realidade foi criada em vista de Jesus Cristo $(\mathrm{Cl} 1,16)$. Com outras palavras, a humanidade de Cristo precedeu e atuou como matriz de todo o gênero humano, constituindo o ser humano querido por Deus. Daí também entendemos a afirmação de João: "O Verbo era a luz verdadeira, que vindo ao mundo ilumina todo homem" (Jo 1,9). Deste modo pôde o Concílio Vaticano II afirmar que "Cristo manifesta o homem ao próprio homem e lhe descobre a sua altíssima vocação" (GS 22) ${ }^{14}$. E esta revelação do que deva ser o homem

\footnotetext{
${ }^{13}$ Nossa proposta ajuda em parte na superação da inevitável diversidade cultural e religiosa. Ver RAMIREZ AGUIRRE, J. I. La formación integral de la Universidad desde la multiculturalidad y el diálogo inter-religioso. Cuestiones Teológicas 89 (2011), p. 155-172.

${ }^{14}$ Este texto conciliar foi o mais citado em todos os pronunciamentos deste papa. Ver SANDER, H.-J. art. cit., p. 740, nota 72. Ver ainda JOÃO PAULO II, Fides et Ratio. São Paulo: Paulinas, 1999 , n. 60.
} 
se encontra na própria vida terrena do Filho de Deus. Pois não apenas assumiu a natureza humana abstratamente falando, mas mostrou ao longo de seus dias o que significa ser realmente humano. Uma existência humana que não pode ser desvinculada de seu projeto de vida, que era o projeto do Pai: fazer irromper na humanidade o Reino de Deus, fazer a vontade do Pai, constituir novos laços entre as pessoas de tal modo que se tornassem uma só família, a família de Deus (Mt 12, 48-50). E isso ele pregou e realizou proporcionando vida, ânimo, perdão, sentido, numa palavra, amor a seus contemporâneos, sobretudo aos mais necessitados. Nada recusou do que constituía o normal da vida humana, participando também de seus momentos de lazer e de alegria, vendo na vida, na natureza, nos eventos, o dom de Deus (Mt 6,25-34).

E mais ainda. Ao relegar a segundo plano as normas religiosas quando em choque com um ser humano necessitado, Jesus desloca o sagrado da esfera religiosa para o âmbito da vida cotidiana, humana, real. Como aparece da parábola do bom samaritano (Lc 10, 25-37) ou da cena do juízo final (Mt $25,34-46)$. No fundo, sagrado é o próprio ser humano e a salvação consiste em se comportar com ele de modo semelhante ao de Jesus Cristo. Mas como experimentamos as tendências egoístas em nossas pessoas necessitamos da graça de Deus, do Espírito Santo que vem nos iluminar e fortalecer, para realizar o que Deus espera de nós. Deste modo a humanização de Deus em Jesus Cristo transcende o simplesmente humano porque supera e elimina qualquer elemento desumanizante ${ }^{15}$. "Todo aquele que segue Cristo, o homem perfeito, torna-se ele também mais homem" (GS 41). Ou nas palavras do papa Francisco: "Chegamos a ser plenamente humanos, quando somos mais do que humanos, quando permitimos a Deus que nos conduza para além de nós mesmos a fim de alcançarmos o nosso ser mais verdadeiro" (EG 8). O cristianismo nada rejeita do humano, mas sim luta contra tudo o que desumaniza a pessoa. Aqui aparece porque a cruz está presente no humano autêntico: amor implica renuncia em favor do outro e incompreensão por parte da sociedade individualista. Portanto o cuidado com o semelhante, o amor fraterno verdadeiro, o compromisso pela vida dos outros, o empenho pela justiça e pela convivência social, são expressões de um autêntico humanismo ${ }^{16}$.

${ }^{15}$ CASTILlO, J. M. La humanización de Dios. Ensayo de Cristología. Madrid: Trotta, 2009, p. 199.

16 Já John Courtney Murray via na formação do humano integral o objetivo educacional da Universidade. Ver GARCIA, K. N. "Reversing the Secularist Drift": John Courtney Murray and the Telos of Catholic Higher Education. Theological Studies 73 (2012), p. 890-908. 
O Concilio Vaticano II expressa claramente esta conclusão ao tratar da atividade humana no mundo na Constituição Pastoral Gaudium et Spes. "Aquele empenho gigantesco no qual os homens se esforçam no decorrer dos séculos para melhorar as suas condições de vida, considerado em si mesmo, corresponde ao plano de Deus" (GS 34). Contudo esta promoção humana não significa simplesmente o progresso tecnológico, que mal utilizado pode mesmo destruir a humanidade (GS 37), mas enquanto concretiza os valores da dignidade humana, da comunidade fraterna e da liberdade e enquanto corresponde ao projeto do Reino de Deus, será conservado, purificado de toda impureza, na outra vida em Deus (GS 39). O Concílio reconhece nas aspirações generosas de todos por tornar mais humana a própria existência a ação salvífica do Espírito Santo (GS 38). Afirmação importante por não restringir aos cristãos a presença atuante de Deus, dando uma conotação teológica ao empenho de todos que militam pela paz, pela justiça, pela mútua ajuda, pelos mais pobres. Não se trata de uma atitude e de um comportamento sem valor diante de Deus, sem uma conotação salvífica, já que manifestada e realizada na pessoa de Jesus Cristo ${ }^{17}$.

Esta conclusão é ainda mais valorizada se temos diante dos olhos a atual cultura marcada pelo culto à eficiência e à produtividade, submissa ao dinheiro e ao consumismo, mesmo que às custas da pessoa humana diminuída em sua dignidade. Sem dúvida a missão do cristianismo hoje é também humanizar esta sociedade, ajudando nossos contemporâneos a encontrar o sentido de sua própria dignidade, de sua liberdade, de sua transcendência. Nesta luta se encontra Deus ${ }^{18}$, um Deus cujo projeto do Reino é uma humanidade feliz, porque guiada pelo amor fraterno e pela justiça. Tendo presente o que implica a salvação cristã segundo os Evangelhos, pôde um teólogo afirmar: "quando trabalhamos pela humanização do homem, trabalhamos pela salvação da humanidade" 19 .

Naturalmente trata-se de uma humanização integral, segundo o projeto de Deus, para não condenarmos o ser humano a um humanismo fechado, horizontal, imanente, esquecidos do que já dizia Pascal: "o homem ultrapassa infi-

\footnotetext{
${ }^{17}$ SMULDERS, P. “A Atividade Humana no Mundo”. In: G. BARAÚNA (ed.), A Igreja no Mundo de Hoje. Petrópolis: Vozes, 1967, p. 312-336, aqui p. 330.

${ }^{18}$ PAPA FRANCISCO: "A presença de Deus acompanha a busca sincera que indivíduos e grupos efetuam para encontrar apoio e sentido para a sua vida. Ele vive entre os citadinos promovendo a solidariedade, a fraternidade, o desejo de bem, de verdade, de justiça" (PAPA FRANCISCO. Evangelii Gaudium. São Paulo: Paulinas, 2013, n. 71).

${ }^{19}$ MOINGT, J. Faire bouger l'Église catholique. Paris: Desclée de Brouwer, 2012, p. 131.
} 
nitamente o homem"20. Pois a razão está voltada para o infinito que possibilita o seu próprio conhecer sem a menor possibilidade de ser objeto de conhecimento, como um horizonte jamais alcançável, portanto incompreensível. Este mistério é intrínseco ao ser humano, que se torna deste modo um mistério para si mesmo. O que as ciências humanas dele dizem não chega a este núcleo do próprio "eu", o que vale não só para mim, como também para meu semelhante. Fechar este acesso ao infinito é cancelar o acesso a Deus, ou reduzi-lo a mais um ídolo conceitual ${ }^{21}$.

\section{Conclusão}

Diante de uma temática tão complexa como é hoje a identidade e a missão da Universidade Católica, sendo a própria identidade caracterizada pela missão, optamos desde o início desta reflexão por um objetivo mais modesto e limitado. Como levar a cabo a missão de oferecer uma visão unitária de cunho cristão para a grande diversidade plural de racionalidades e disciplinas presentes em nossos campos universitários? Intencionalmente buscamos um enfoque mais pastoral do que teórico ou acadêmico. Deste modo evitamos longas discussões entre razão e fé, entre a universalidade da Academia e a confessionalidade da fé cristã ${ }^{22}$, entre a autonomia da pesquisa científica e o juízo ético sobre a mesma, entre a liberdade acadêmica e a autoridade eclesiástica. Nosso objetivo foi simplesmente oferecer uma base comum para o diálogo e a colaboração mútua que, respeitando a diversidade cultural e religiosa, constituísse uma temática que realmente tocasse e interessasse a todos.

Daí termos proposto como objetivo o próprio humano integral que, num primeiro momento, não necessita ser apresentado explicitamente em toda a sua amplitude, o que já faria entrar os elementos cristãos em sua compreensão. Este procedimento se justifica não por uma razão de estratégia ou de oportunismo, mas simplesmente porque muitos valores invocados em defesa do "humano" possuem raízes cristãs, embora não invocados como tais. Além disso, como vimos, a ação do Espírito Santo pelo Reino de Deus não se limita apenas aos cristãos, mas atinge todo ser humano que assuma a causa do Reino por uma

\footnotetext{
${ }^{20}$ PASCAL, B. Pensées. Paris: Seuil, 1962, § 131.

${ }^{21}$ MARION, J. L. "La raison formelle de l'infini”. In: J. L MARION, Le croire pour le voir, p. 55-74.

${ }^{22}$ É conhecida a afirmação de Bernard Shaw que uma Universidade Católica é uma contradição nos termos. O nosso enfoque, mesmo sem pretender tal, já a relativiza bastante.
} 
humanidade mais fraterna e justa. Num segundo momento a fonte cristã do autêntico humanismo será apresentada, o querigma salvífico, a pessoa de Jesus Cristo, sua vida, sua mensagem, com tudo o que tem de positivo, de motivador, de apelo à liberdade, de alegria, de realização profunda do ser humano.

Uma outra questão que ultrapassa nosso objetivo diz respeito ao modo pelo qual pode ser concretizada nossa proposta. Naturalmente poderão se apresentar várias modalidades conforme a realidade de cada Universidade Católica, conforme os desafios que enfrenta, os recursos que dispõe e os professores competentes com que pode contar. Longe de eliminar a pastoral tradicional a partir de uma evangelização explícita e de uma prática sacramental, ela constitui como que uma etapa de preparação para a mencionada pastoral que, no fundo, apenas explicita na doutrina e celebra no sacramento a atitude fundamental cristã do amor fraterno, ou do empenho pelo ser humano. Deste modo não substitui, mas, pelo contrário, fundamenta e esclarece o sentido destas manifestações de cunho religioso ${ }^{23}$.

Numa época em que a Igreja procura escutar a sociedade, as demais religiões e até mesmo aqueles que professam não ter fé, nossa sugestão oferece um terreno fecundo para este diálogo, constituindo mesmo uma modalidade do que hoje chamamos o "pátio dos gentios"24. Pois também devemos dialogar com os ateus, como nos ensina o Concílio Vaticano II (GS 92), e certamente deles também aprender como declara o mesmo Concílio (GS 44).

\section{Referências bibliográficas}

BUCKLEY, M. J. The Catholic University as Promise and Project. Washington: Georgetown University Press, 2007.

CASTILlO, J. M. La humanización de Dios. Ensayo de Cristologia. Madri: Trotta, 2009.

DUPRÉ, L. L'autre dimension. Essai de philosophie de la religion. Paris: Cerf, 1977.

\footnotetext{
${ }^{23}$ Sabemos que os estudantes universitários chegam com representações religiosas que não resistem aos novos conhecimentos que então adquirem, já que tais representações refletem o que aprenderam como crianças. Daí a crise que experimentam. Apontar o núcleo da fé cristã muito os ajudaria a assumir uma fé adulta.

${ }^{24}$ Ver, como exemplo, RAVASI, GIANFRANCO; FERRY, LUC. Il Cardinale e il Filosofo. Dialogo su fede e ragione. Milano: Mondatori, 2013.
} 
FRANCISCO. P.P. Evangelii Gaudium. São Paulo: Paulinas, 2013.

GARCIA, K. N. "Reversing the Secularist Drift": John Courtney Murray and the Telos of Catholic Higher Education. Theological Studies 73 (2012), pp. 890-908.

HAIGHT, R. Dinâmica da Teologia. São Paulo: Paulinas, 2004.

JOÃO PAULO II. Fides et Ratio. São Paulo: Paulinas, 1999.

KOMONCHAK, J. A. Modernity and the Construction of Roman Catholicism. Cristianesimo nella Storia 18 (1997), pp. 353-385.

LOHFINK, G. Deus precisa da Igreja? Teologia do povo de Deus. São Paulo: Loyola, 2008.

LOHFINK, G. Jesus von Nazareth. Was er wollte, wer er war. Freiburg: Herder, 2011.

LOHFINK, G. Jesus of Nazareth. What He Wanted, Who He Was. Collegeville: Liturgical Press, 2012.

MARION, J.-L. "La raison formelle de l'infini”. In: J.-L. Marion, Le croire pour le voir. Paris: Parole et Silence, 2010, pp. 55-74.

MARION, J.-L. "Le service de la rationalité dans l'Église”. In: J.-L. Marion, Le croire pour le voir. Paris: Parole et Silence, 2010, pp. 101s.

MIRANDA, M. F. Igreja e sociedade. São Paulo: Paulinas, 2009.

MOINGT, J. Faire bouger l'Église catholique. Paris: Desclée de Brouwer, 2012.

PASCAL, B. Pensées. Paris: Seuil, 1962.

PEREIRA, E. M. A. A Universidade da modernidade nos tempos atuais. Avaliação 1 (2009), pp. 29-52.

RAMIREZ AGUIRRE, J. I. La formación integral de la Universidad desde la multiculturalidad y el diálogo inter-religioso. Cuestiones Teológicas 89 (2011), pp. 155-172.

RAVASI, G.; FERRY, LUC. Il Cardinale e il Filosofo. Dialogo su fede e ragione. Milano: Mondatori, 2013.

ROLLET, J. “Religion et foi. L'actualité d'une différence”. In: J. Doré - Ch. 
Theobald. (dir.), Penser la Foi. Mélanges offerts à Joseph Moingt. Paris: Cerf, 1993, pp. 301-313.

SANDER, H.-J. "Theologischer Kommentar zur Pastoralkonstitution über die Kirche in der Welt von heute Gaudium et Spes". In: P. Hünermann B.-J. Hilberath (Hrsg.), Herders Theologischer Kommentar zum Zweiten Vatikanischen Konzil 4. Freiburg: Herder, 2005, pp. 581-886.

SCHICKENDANTZ, C. Una elipse con dos focos: hacia un nuevo método teológico a partir de Gaudium et Spes. Revista Teología 50 (2013), pp. 89-109.

SMULDERS, P. “A Atividade Humana no Mundo”. In: G. Baraúna (ed.), $A$ Igreja no Mundo de Hoje. Petrópolis: Vozes, 1967, pp. 312-336.

ZAMAGNI, S. A identidade e a missão de uma universidade católica na atualidade. Cadernos IHU Ideias 11 (2013), pp. 5-8.

Mario de França Miranda

Doutor em Teologia Sistemática pela Pontificia Università Gregoriana (Roma) Professor de Teologia na Pontifícia Universidade Católica do Rio de Janeiro

Rio de Janeiro / RJ - Brasil E-mail: mfranca@puc-rio.br

Recebido em: 13/11/14

Aprovado em: 19/12/14 